\title{
Prognostic value of P53 nuclear overexpression in bladder cancer
}

\author{
Reddy P. $\mathbf{V}^{1}$ \\ ${ }^{1}$ Dr P. Vedamurthy Reddy, Associate Professor, Dept of Urology \& Renal Transplantation, Narayana Medical \\ College \& Hospital, Nellore, Andhra Pradesh, India - 524003
}

Address for Correspondence: Dr P. Vedamurthy Reddy, E Mail: pglreddy@yahoo.co.in

\begin{abstract}
Introduction: Urinary bladder cancer is one of the common genitourinary malignancy presenting to the urology department. Prognosis of these patients will depend upon the number of clinicopathological factors. Overexpression of p53 is associated with aggressive behaviour of bladder cancer. The purpose of the present study is to assess the role of p53 tumour suppressor gene as an independent prognostic marker. Materials \& Methods: Thirty-three (33) consecutive cases of urinary bladder cancer attending Department of Urology between August 2006 to December 2008 were studied. In this study P53 protein, nuclear over expression was assessed in Formalin-fixed, paraffin-embedded tissue sections by the immunohistochemical method using monoclonal antibody. This p53 nuclear over expression was correlated with tumour grade and stage. Over all survival rate was assessed in p53 positive and negative patients. Results: Two patients with T1G1 tumours developed recurrence with initial TURBT and intravesical BCG instillation after 6 months and responded to Re TURBT and intravesical BCG instillation therapy. One patient of T1G3 developed recurrence after 1 year with initial TURBT and intravesical BCG instillation and responded to Re TURBT and intravesical BCG instillation therapy. One patient of T1G3 progressed to muscle invasive disease after 1 year and underwent Radical cystoprostatectomy with ileal conduit received adjuvant chemotherapy and radiotherapy. Two patients developed post-operative urinary leak and underwent bilateral cutaneous ureterostomy. Nine patients died in followup period. Conclusion: There was a strong positive correlation between the expression of mutant p53 and tumour grade, with none of the low-grade tumours were positive for mutant p53, in contrast to $60 \%$ of highgrade tumours. In this study, there was no significant difference in the mortality between p53 positive and negative patients.
\end{abstract}

Key Words: Bladder cancer; p53 nuclear overexpression; Tumor grade, Immunohistochemistry

\section{Introduction}

Bladder cancer is one of the commonest malignancies which can occur at any age and involve both sexes, though predominantly affecting middle-aged and elderly males. In men, it is the fourth most common cancer after prostate, lung and colorectal cancers, accounting for $6.6 \%$ of all cancer cases [1]. In women, it is the ninth most common cancer, accounting for $2.4 \%$ of all cancers [1]. Bladder cancer accounts for $3.0 \%$ of all cancer deaths in men and $1.5 \%$ in women. Males have higher 5 year survival rates than women. In adolescents and in adults younger than 30-40 years, bladder cancers tend to express well-differentiated

Manuscript received: $4^{\text {th }}$ June 2017 Reviewed: $15^{\text {th }}$ June 2017

Author Corrected: $24^{\text {th }}$ June 2017

Accepted for Publication: $30^{\text {th }}$ June 2017 histologies and behave in a more indolent fashion [2]. Regional and national differences reflect the combined effects of environmental and hereditary factors. It also reflects national differences in case reporting [3]. The important molecular mechanism in the process of carcinogenesis is the inactivation of genes coding for proteins that regulate cell growth, DNA repair or apoptosis.

Deletions or inactivation of these so-called cancer suppressor genes could encourage unregulated growth or failure to direct damaged DNA cells to programmed cell death, ultimately resulting in uncontrolled proliferation of genetically altered clones. Several suppressor gene loci have been closely associated with bladder cancer. These 
include p53 on chromosome $17 \mathrm{p}$, retinoblastoma $(\mathrm{Rb})$ gene on chromosome $13 \mathrm{q}$, and genes on chromosome 9 .

P53: The p53 gene is the most frequently altered gene in human cancers [4,5]. The normal protein, wild-type $\mathrm{p} 53$, has a variety of functions including 1) acting as a transcription factor that suppresses cell proliferation, 2) directing DNA damaged cells toward apoptosis before DNA replication (S-phase of cell cycle) occurs, 3 ) contributing to the repair of damaged DNA by inducing the production of deoxyribonucleotide triphosphates in the nucleus and other mechanisms $[4,5,6,7,8]$.

P53 mutations have been associated with genomic instability and hence progressive development of further mutations. Bladder cancers with p53 abnormalities appear to have more aggressive behaviours. For tumours to exceed 1 or $2 \mathrm{~mm}$ in diameter, new blood vessels must feed them. Wildtype p53 induces the expression of a potent inhibitor of angiogenesis, thrombospondin-1 (TSP1), a normal constituent of the extracellular matrix, where as mutant (or absent) p53 does not. A correlation of abnormal p53 immunostaining with down-regulation of TSP-1 and neoangiogenesis has been reported in bladder cancer [9].

MDM-2, whose expression itself is induced by p53, binds to p53's aminoterminal, targeting it for ubiquitization and proteosomal degradation [10]. Failure of this process stabilises p53. Indeed, wildtype p53 normally lasts only very briefly in the cell nucleus, where as mutated forms often accumulate for longer times and hence are more easily detected by immunohistochemistry (IHC) [11].

The wild-type p53 protein functions as a tetramer, the altered product of a mutant allele stabilise but inactivates the tetrameric protein and resulting in tumorigenesis.

Urinary bladder cancer is one of the common genitourinary malignancies presenting to the urology department. Prognosis of these patients will depend upon the number of clinicopathological factors. Overexpression of p53 is associated with aggressive behaviour of bladder cancer. The purpose of the present study is to assess the role of p53 tumour suppressor gene as an independent prognostic marker.

\section{Materials \& Methods}

Study design - Thirty-three (33) consecutive cases of urinary bladder cancer attending Department of Urology between August 2006 to December 2008 were studied. A detailed history was taken and clinical examination was done for all patients which were included in the study. Urine was sent for routine microscopy, culture sensitivity and urine cytology. Routine blood parameters like hemogram, serum urea, serum creatinine, blood sugar and coagulation profile were done. Ultrasound abdomen, Contrast enhanced computer tomography (CECT) abdomen and plain CT abdomen in patients with renal failure were done for diagnosis of bladder tumours and for clinical staging.

Patients were managed according to the stage and general condition with bladder tumour biopsy, transurethral resection of bladder tumour (TURBT) and Radical cystectomy with urinary diversion followed by adjuvant intravesical BCG instillation, chemotherapy and /or radiotherapy depending upon the pathological stage. Pathological specimens sent for histopathological examination and immunohistochemistry(IHC) for p53.

P53 nuclear overexpression in Formalin-fixed, paraffin-embedded tissue sections has been detected by the immunohistochemical method using monoclonal antibody. The monoclonal antibody used is Monoclonal mouse anti-human p53 protein clone D0-7 and code No. M 7001. Monoclonal mouse antibody supplied in liquid form as tissue culture supernatant (RPM/1640 medium containing fetal calf serum) dialysed against $0.05 \mathrm{M}$ Tris/ $\mathrm{HCl}$, PH 7.2 containing $15 \mathrm{mM}$ NaN3. Mouse Ig concentration is $400 \mathrm{mg} / \mathrm{L}$, isotype is Ig G2b, Kappa and total protein concentration are $13.7 \mathrm{~g} / \mathrm{L}$. Immunogen used was recombinant human wild-type p53 protein expressed in E.coli. Monoclonal antibody recognises an epitope in the N-terminus of the human p53 protein. The epitope for the antibody is known to reside between amino acids 19 to 26 .

The antibody reacts with wild type and mutant type of p53 protein. Overexpression is defined as tumour with $>20 \%$ of cells with positive nuclear reactivity. To improve the staining pattern methods for antigen retrieval, such as boiling in $10 \mathrm{mM}$ citrate buffer, can be used. This p53 nuclear 
overexpression is correlated with tumour stage and grade. Tumour staging according to revised TNM system AJCC-UICC 1997. Follow up done with urine cytology and cystoscopy quarterly for 1 year, semi-annual for 2 years and then annually for highgrade tumours (including CIS).

Inclusion criteria- All the patients who attended urology OPD with diagnosis of bladder cancer

Exclusion criteria- All patients who underwent prior treatment for bladder cancer
Statistical analysis- Statistical analysis was performed using SPSS package (version window 11.5 package). One way analysis of variance (ANOVA) was used to estimate the differences between the study groups.

Probability value $\mathrm{P}<0.05$ was considered significant. Kaplan-Meier curve was drawn to assess the survival rate in p53 positive and negative patients. All-cause mortality was taken for survival.

\section{Results}

The total numbers of patients were 33 in this study. Males were 27 and female were 6 . More than $50 \%$ of patients were above 60 years of age. No patient was seen below 30 years of age. Histopathology type was Transitional cell carcinoma 30 (91.91\%), Transitional cell carcinoma with sarcomatoid change 1 (3.03\%), Squamous cell carcinoma 1 (3.03\%), Leiomyosarcoma 1 (3.03\%), and grade was low-grade tumours 8 (24.24) and high-grade tumours 25 (75.26\%). Patients were treated with Transurethral bladder biopsy $2(6.06 \%)$, Transurethral resection of bladder tumour (TURBT) 31 (93.94\%), Radical cystectomy with ileal conduit 9 (27.27\%), and Radical cystectomy + total urethrectomy and continent ileal double ' $\mathrm{T}$ ' pouch 1 (3.03\%). Patients with superficial bladder cancer received adjuvant intravesical BCG instillation $13(39.39 \%)$ and patients with nodal involvement received adjuvant chemotherapy3 (9.09\%).Primary radiotherapy given to the patients with the poor general condition and who refuses radical cystectomy and urinary diversion7 (21.21\%).

P53 nuclear overexpression is defined as tumour with $>20 \%$ of cells with positive nuclear reactivity. The number of patients with p53 negativity was 18 (54.55\%) and the number of patients with p53 positivity was 15 (45.45\%). There was a positive correlation between the expression of mutant p53 protein and tumour stage, with only 2 of 10 PT1 tumours being positive for mutant p53 compared with 13 (56.52\%) of 23 muscle invasive and CIS (Fig:1). There was a positive correlation between the expression of mutant p53 protein and tumour grade, with none of 8 low-grade tumours were positive for mutant p53, in contrast to 15 (60\%) of 25 high-grade tumours. Two patients with T1G1 tumours developed recurrence with initial TURBT and intravesical BCG instillation after 6 months and responded to Re TURBT and intravesical BCG instillation therapy. One patient of T1G3 developed recurrence after 1 year with initial TURBT and intravesical BCG instillation and responded to

Survival Curve in p53 Postive Vs Negative patients

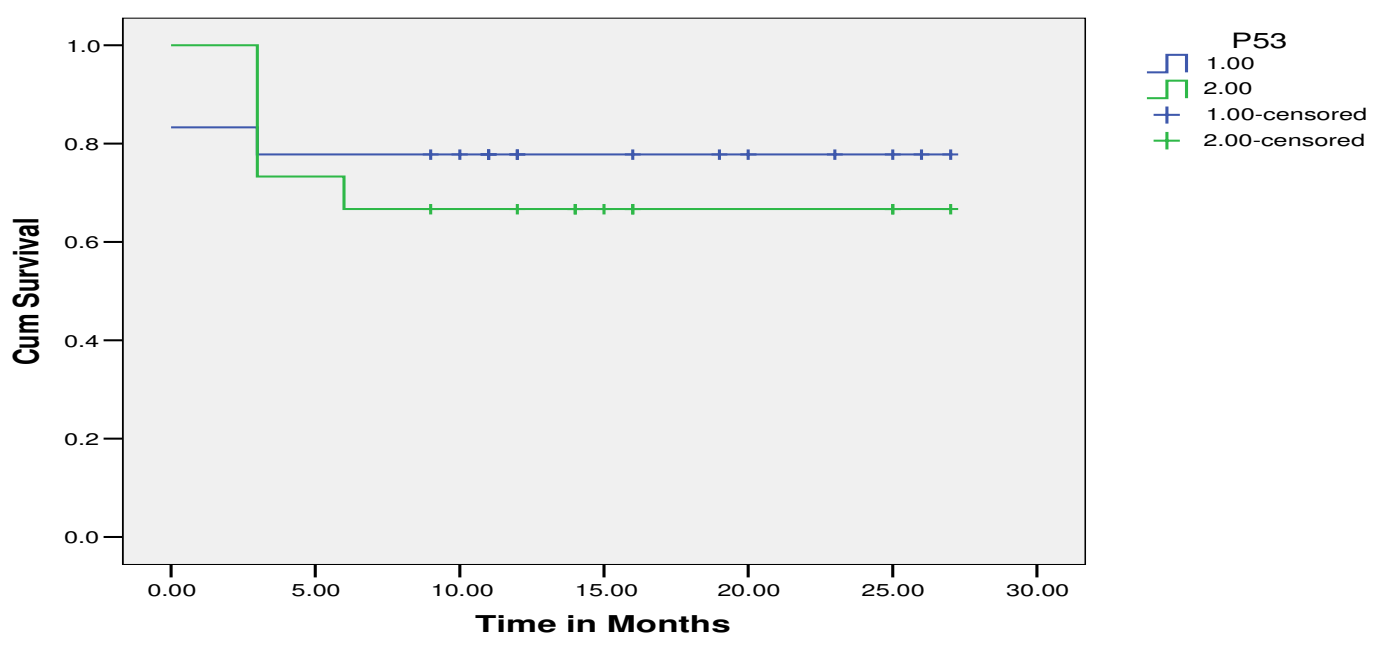

Table-1: This curve shows that survival rate of p53 positive patients is lesser than p53 negative patients (Note: Green line is the survival rate of p53 positive, while blue line is that of p53 negative patients). 
Re TURBT and intravesical BCG instillation therapy. One patient of T1G3 progressed to muscle invasive disease after 1 year and underwent Radical cystoprostatectomy with ileal conduit. Received adjuvant chemotherapy and radiotherapy. Two patients developed post-operative urinary leak and underwent bilateral cutaneous ureterostomy. Mortality in p53 positive patients was 5 and Mortality in p53 Negative patients was 4 (Table:1). 8 out of 9 patients expired have transitional cell carcinoma and 1 had sarcomatoid carcinoma. All patients have high-grade and muscle invasive (T2 and/ or high stage) tumours and more than $50 \%$ were p53 positive.

\section{Correlations}

Table-2: ANOVA Test (one-way analysis of variance) to determine the statistical difference of all variables between parameters.

\begin{tabular}{|c|c|c|c|c|c|c|c|}
\hline & & T-Stage & N-Stage & M-Stage & Grade & P53 & Survival \\
\hline \multirow{4}{*}{ T-Stage } & Pearson Correlation & 1.000 & 0.181 & -0.021 & $0.398^{*}$ & 0.129 & 0.140 \\
\cline { 2 - 8 } & Sig. (2-tailed) &. & 0.313 & 0.908 & 0.022 & 0.473 & 0.437 \\
\cline { 2 - 8 } & N & 33 & 33 & 33 & 33 & 33 & 33 \\
\hline \multirow{5}{*}{ N-Stage } & Pearson Correlation & 0.181 & 1.000 & -0.087 & 0.277 & -0.078 & $0.388^{*}$ \\
\cline { 2 - 8 } & Sig. (2-tailed) & 0.313 & & 0.631 & 0.118 & 0.665 & 0.026 \\
\cline { 2 - 8 } & N & 33 & 33 & 33 & 33 & 33 & 33 \\
\hline \multirow{5}{*}{ Grade } & Pearson Correlation & -0.021 & -0.087 & 1.000 & 0.100 & -0.161 & 0.289 \\
\cline { 2 - 8 } & Sig. (2-tailed) & 0.908 & 0.631 & & 0.580 & 0.370 & 0.103 \\
\cline { 2 - 8 } & N & 33 & 33 & 33 & 33 & 33 & 33 \\
\cline { 2 - 8 } & Sig. (2-tailed) & 0.022 & 0.118 & 0.580 & & 0.002 & 0.048 \\
\cline { 2 - 8 } & N & 33 & 33 & 33 & 33 & 33 & 33 \\
\hline \multirow{5}{*}{ P53 } & Pearson Correlation & 0.129 & -0.078 & -0.161 & $0.516^{*}$ & 1.000 & 0.124 \\
\cline { 2 - 8 } & Sig. (2-tailed) & 0.473 & 0.665 & 0.380 & 0.002 & & 0.491 \\
\cline { 2 - 8 } & N & 33 & 33 & 33 & 33 & 33 & 33 \\
\hline \multirow{4}{*}{ Survival } & Pearson Correlation & 0.140 & $0.388^{*}$ & 0.289 & $0.346^{*}$ & 0.124 & 1.000 \\
\cline { 2 - 8 } & Sig. (2-tailed) & 0.437 & 0.026 & 0.103 & 0.048 & 0.491 & 33 \\
\cline { 2 - 8 } & N & 33 & 33 & 33 & 33 & 33 & 33 \\
\hline
\end{tabular}

*correlation is significant at the 0.05 level (2-tailed).

***orrelation is significant at the 0.01 level (2-tailed).

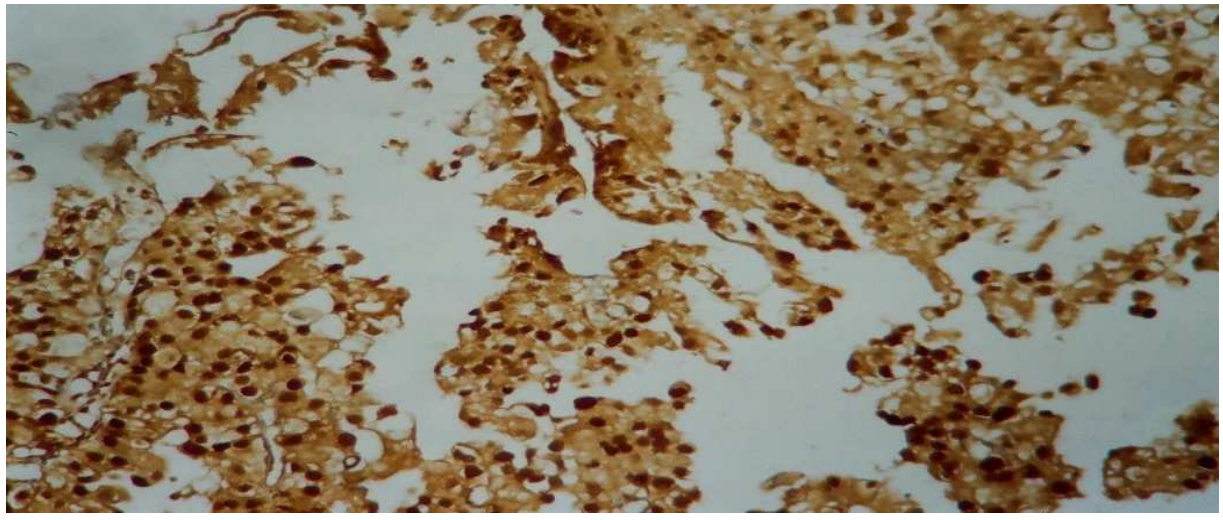

Fig-1: Carcinoma in situ Immunohistochemistry (IHC) showing p 53 positivity

ANOVA Test (one-way analysis of variance) was done to determine the statistical difference of all variables between parameters. The correlation was significant between tumour grade and P53 positivity. $\mathrm{P}$ value is $<0.05$. There was no significant correlation between P53 and tumour stage, study correlation coefficient (r) between P53 and tumour stage was 0.129 and p-value 0.473 , which was not significant (Table:2). 


\section{Discussion}

The most useful prognostic parameters in bladder cancer for tumour recurrence and subsequent cancer progression in the patient with superficial tumours are tumour grade, stage, lymphatic invasion, tumour size, carcinoma in-situ in neighbouring or distant urothelial areas, papillary or solid tumour architecture, multifocality and frequency of tumour recurrences.

The most important of these are tumour grade, stage and presence of carcinoma in-situ. In this study P53 protein nuclear overexpression was assessed in Formalin-fixed, paraffin-embedded tissue sections by the immunohistochemical method using monoclonal antibody. This p53 nuclear overexpression was correlated with tumour grade and stage. Overall survival rate was assessed in $\mathrm{p} 53$ positive and negative patients.

Abnormal expression of the receptor for EGF on malignant urothelium correlates with increased tumor aggressiveness and is a predictor of poor survival from disease $[12,13,14]$. Transforming growth factor - $\beta$ s (TGE- $\beta$ s) compose a family of related proteins that include TGF - $\beta 1$ to $\beta 5$, mullerian inhibitory substance, inhibin and activin [15]. Tumors with elevated expression of TGF- $\beta$ (particularly TGF- $\beta 1$ ) would have slower proliferation and be more indolent than those with reduced expression. This has been found using Northern blotting to detect TGF- $\beta 1$ and TGF - $\beta 2$ in mRNAs by coombs and colleagues [16].

Deletions of chromosome $17 \mathrm{p}$ have been associated with tumor progression - presumably because TP 53 is lost with the section of $17 \mathrm{p}$ that is deleted. Others have looked at increased immunohistochemical detectability of TP 53 in the nucleus as a surrogate for genetic deletion and /or mutation [11]. Esrig and colleagues demonstrated that increased nuclear expression of TP 53 in formalin - fixed, paraffin-embedded sections of TCCs from patients undergoing cystectomy correlated with reduced survival and disease progression [17].

Several studies have failed to find prognostic value of nuclear overexpression of TP53, independent of tumor grade and stage, in patients with superficial bladder tumors $[2,18,19,20]$. In part, this reflects variations in reagents, tissue preparations, means of quantification, and thresholds of positivity that various researchers have employed. The lack of technologic consensus on these issues has significantly reduced widespread acceptance of the prognostic utility of TP53 status.

There was a strong positive correlation between the expression of mutant p53 and tumour grade, with none of the low grade tumours were positive for mutant p53, in contrast to $60 \%$ of high-grade tumours. There was there no significant correlation between $\mathrm{p} 53$ and tumour stage. $\mathrm{P}$ value was $>0.05$, which is not significant. It is possible that because of small sample size we may not have got the significant association between tumour stage and p53 positivity.

For superficial and invasive cancers, expressions of multiple markers, particularly TP 53 and either RB or $\mathrm{p} 21$, have been investigated with variable results $[6,21]$. The high frequency of loss of heterozygosity at chromosome $17 \mathrm{p}$ in high grade Transitional cell carcinoma (TCC). Genetic defects in p53 locus have been shown to correspond with protein expression of the mutated p53 gene product. The $\mathrm{p} 53$ gene encodes for a protein vital to arresting the cell cycle. Mutations in p53 result in the production of a dysfunctional protein product with longer half-life than the wild - type protein. Because of this protein longevity, p53 mutated gene products accumulate in the cell nucleus and can be easily detected by immunohistochemical methods [22].

In this study, there was no significant difference in the mortality between p53 positive and negative patients. $\mathrm{P}$ value was $>0.05$, which was not significant. Though percentages are shown significance yet ' $\mathrm{P}$ ' values did not yield significant because of the small group of patients encountered during our study.

\section{Conclusion}

There was a positive correlation between the tumour grade and p53 nuclear overexpression. There was no significant difference in the mortality between the p53 positive and negative tumours. Only half of the tumours with high grade and high stage are associated with P53 nuclear 
overexpression. This study concludes that p53 nuclear overexpression was not clinically useful as an independent prognostic marker for bladder cancer. It can be used along with tumour grade and stage.

\section{Funding: Nil, Conflict of interest: None Permission of IRB: Yes}

\section{References}

1. Jemal A, Murray T, Ward E, Samuels A, Tiwari RC, Ghafoor A, Feuer EJ, Thun MJ. Cancer statistics, 2005. CA Cancer J Clin. 2005 Jan-Feb; 55 (1):10-30.

2. Linn JF, Sesterhenn I, Mostofi FK, Schoenberg M. The molecular characteristics of bladder cancer in young patients. J Urol. 1998 May;159(5):1493-6.

3. Crow P, Ritchie AW. National and international variation in the registration of bladder cancer. BJU Int. 2003 Oct;92(6):563-6.

4. Harris CC, Hollstein M. Clinical implications of the p53 tumor-suppressor gene. N Engl J Med. 1993 Oct 28;329(18):1318-27.

5. Vogelstein B. Cancer. A deadly inheritance. Nature. 1990 Dec 20-27;348(6303):681-2.

6. Cote RJ, Chatterjee SJ. Molecular determinants of outcome in bladder cancer. Cancer J Sci Am. 1999 Jan-Feb;5(1):2-15.

7. Lozano G, Elledge SJ. p53 sends nucleotides to repair DNA. Nature. 2000 Mar 2; 404 (6773): 24-5.

8. Smith ML, Chen IT, Zhan Q, Bae I, Chen CY, Gilmer TM, Kastan MB, O'Connor PM, Fornace AJ Jr. Interaction of the p53-regulated protein Gadd45 with proliferating cell nuclear antigen. Science. 1994 Nov 25;266(5189):1376-80.

9. Grossfeld GD, Ginsberg DA, Stein JP, et al: Thrombospondin-1 expression in bladder cancer: Association with p53 alterations, tumour angiogenesis, and tumour progression. J Natl Cancer Inst 1997; 89:219-27.

10. Carr AM. Cell cycle. Piecing together the p53 puzzle. Science. 2000 Mar 10;287(5459):1765-6.
11. Finlay CA, Hinds PW, Tan TH, Eliyahu D, Oren M, Levine AJ. Activating mutations for transformation by $\mathrm{p} 53$ produce a gene product that forms an hsc70-p53 complex with an altered halflife. Mol Cell Biol. 1988 Feb;8(2):531-9.

12. Messing EM, Reznikoff CA. Normal and malignant human urothelium: in vitro effects of epidermal growth factor. Cancer Res. 1987 May 1; 47(9):2230-5.

13. Neal DE, Sharples L, Smith K, et al: The epidermal growth factor receptor and the prognosis of bladder cancer. Cancer 1990; 65:1619-25.

14. Popov Z, Gil-Diez-De-Medina S, Ravery V, et al: Prognostic value of EGF receptor and tumor cell proliferation in bladder cancer: Therapeutic implications. Urol Oncol 2004; 22:93-101.

15. Roberts AB, Sporn MB. Physiological actions and clinical applications of transforming growth factor-beta (TGF-beta). Growth Factors. 1993;8 (1):1-9.

16. Coombs LM, Pigott DA, Eydman DA, et al: Reduced expression of TGF $\beta$ is associated with advanced disease in transitional cell carcinoma. $\mathrm{Br}$ J Cancer 1993; 67(3):578-584.

17. Esrig D, Elmajian D, Groshen S, Freeman JA, Stein JP, Chen SC, Nichols PW, Skinner DG, Jones PA, Cote RJ. Accumulation of nuclear p53 and tumor progression in bladder cancer. N Engl J Med. 1994 Nov 10;331(19):1259-64.

18. Gardner RA, Walsh MD, Allen V, et al: Immunohistological expression of p53 in primary pT1 transitional cell bladder cancer in relation to tumor progression. Br J Urol 1994; 73:526-32.

19. Lebret $\mathrm{T}$, Becette $\mathrm{V}$, Barbagelatta $\mathrm{M}$, et al: Correlation between p53 overexpression and response to bacillus Calmette-Guérin therapy in a high risk select population of patients with pT1G3 bladder cancer. J Urol 1998; 159:788-91.

20.Lipponen PK. Over-expression of p53 nuclear oncoprotein in transitional-cell bladder cancer and its pro gnostic value. Int J Cancer. 1993 Feb 1;53(3):365-70. 
21. Cordon-Cardo C: Mutation of cell cycle regulators-biological and clinical implications for human neoplasia. Am J Pathol 1995; 147(3): 545-60.
22. Olumni AF, Tsai YC, Nichols PW, et al: Allelic loss of chromosome $17 \mathrm{p}$ distinguishes high grade from low grade transitional cell carcinomas of the bladder. Cancer Res 1990; 50:7081-3.

\section{How to cite this article?}

Reddy P. V. Prognostic value of P53 nuclear overexpression in bladder cancer. Int J Med Res Rev 2017;5(06):569-575. doi:10.17511/ijmrr. 2017.i06.05. 